Studies in the Philosophy of Sociality 12

Tiziana Andina

Petar Bojanić Editors

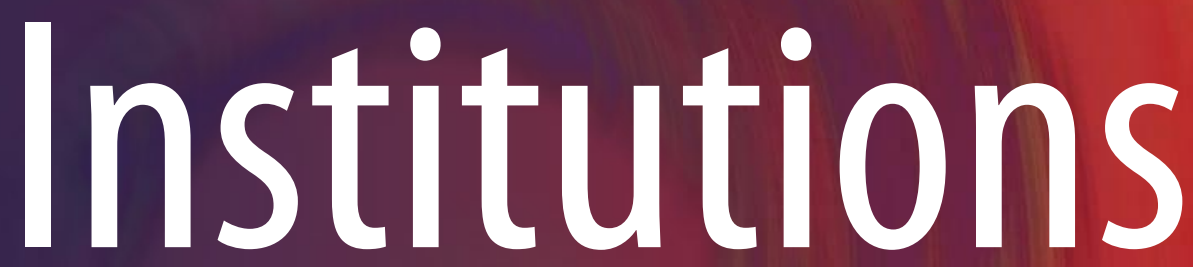

in Action

The Nature and the Role of Institutions in the Real World 


\section{Studies in the Philosophy of Sociality}

\section{Volume 12}

\section{Series Editor}

Raul Hakli, Dept of Political \& Economic Studies, University of Helsinki, Helsinki, Finland

\section{Managing Editors}

Hans Bernhard Schmid, University of Basel, Basel, Switzerland

Jennifer Hudin, University of California, Berkeley, USA

\section{Advisory Editors}

Robert Audi, Department of Philosophy, Notre Dame University, Notre Dame, USA Michael Bratman, Department of Philosophy, Stanford University, Stanford, USA Cristiano Castelfranchi, Cognitive Science, University of Siena, Siena, Italy

David Copp, University of California, Davis, Davis, USA

Ann Cudd, University of Kentucky, Lexington, USA

John Davis, Marquette University, Milwaukee, USA

Wolfgang Detel, Department of Philosophy, University of Frankfurt, Frankfurt, Germany Andreas Herzig, Computer Science, University of Toulouse, Toulouse, France Ingvar Johansson, Philosophy, Umeå University, Umeå, Sweden Byron Kaldis, Department of Philosophy, University of Athens, Athens, Greece Martin Kusch, Department of Philosophy, University of Vienna, Wien, Austria Christopher Kutz, Law, University of California, Berkeley, USA

Eerik Lagerspetz, Department of Philosophy, University of Turku, Turku, Finland Pierre Livet, Department of Philosophy, Universite de Provence, Marseille, France Tony Lawson, Faculty of Economics, University of Cambridge, Cambridge, UK Kirk Ludwig, Department of Philosophy, University of Florida, Gainesville, USA Kay Mathiessen, Information Science and Philosophy, University of Arizona, Tucson, USA

Larry May, Philosophy Department, Vanderbilt University, Nashville, USA Georg Meggle, Institute of Philosophy, University of Leipzig, Leipzig, Germany Anthonie Meijers, Department of Philosophy, University of Eindhoven, Eindhoven, The Netherlands

Seumas Miller, Philosophy, Australian National University and Charles Sturt University, Canberra, Australia

Uskali Mäki, Academy of Finland, Helsinki, Finland

Elisabeth Pacherie, Cognitive Science, Jean Nicod Institute, Paris, France

Henry Richardson, Department of Philosophy, Georgetown University, Washington D.C., USA

Michael Quante, Department of Philosophy, University of Münster, Münster, Germany John Searle, Department of Philosophy, University of California, Berkeley, USA Michael Tomasello, Department of Developmental Psychology, Max Planck Institute, Leipzig, Germany 
First book series in Philosophy of the Social Sciences that specifically focuses on Philosophy of Sociality and Social Ontology.

Covers a new and rapidly developing field that has become one of the key topics of the international philosophical world.

Aims at an interdisciplinary approach that will bring new perspectives to the study of such topics as communication, unintended consequences of action as well as social structures and institutions.

This book series publishes research devoted to the basic structures of the social world. The phenomena it focuses on range from small scale everyday interactions to encompassing social institutions, from unintended consequences to institutional design. The unifying element is its focus on the basic constitution of these phenomena, and its aim to provide philosophical understanding on the foundations of sociality. Studies in the Philosophy of Sociality covers the part of philosophy of the social sciences which deals with questions of social ontology, collective intentionality (e.g. collective knowledge, joint and collective action, joint mental states) and related philosophical topics. The series will include monographs and edited collections on philosophical and conceptual questions concerning social existence as well as conceptual and theoretical analyses of social notions and collective epistemology.

In principle, all phenomena dealing with sociality are covered as long as they are approached from a philosophical point of view, broadly understood. Accordingly, the works to be published in the series would in general be philosophical-without regard to philosophical schools and viewpoints - and they would meet the highest academic and intellectual standards are met. However, the series is interdisciplinary not only in an intra-philosophical sense but also in the sense of encouraging highlevel work from other disciplines to be submitted to the series. Others who are active in the field are political scientists, economists, sociologists, psychologists, linguists, neuroscientists, evolutionary biologists, and researchers of artificial intelligence.

The resulting interdisciplinary approach will give new perspectives to the study of topics such as social interaction, communication, unintended consequences of action, social structures and institutions, the evolution of collective intentionality phenomena, as well as the general ontological architecture of the social world.

The series discourages the submission of manuscripts that contain reprints of previous published material and/or manuscripts that are below 150 pages / 75,000 words.

For inquiries and submission of proposals authors can contact christi.lue@springer.com, or contact one of the associate editors.

More information about this series at http://www.springer.com/series/10961 
Tiziana Andina • Petar Bojanić

Editors

\section{Institutions in Action}

The Nature and the Role of Institutions in the Real World

黛 Springer 


\section{Editors}

Tiziana Andina

Department of Philosophy and Educational

Sciences

University of Turin

Torino, Italy

\author{
Petar Bojanić \\ Institute for Philosophy and Social Theory \\ University of Belgrade \\ Belgrade, Serbia
}

ISSN 2542-9094

ISSN 2542-9108 (electronic)

Studies in the Philosophy of Sociality

ISBN 978-3-030-32617-3

ISBN 978-3-030-32618-0 (eBook)

https://doi.org/10.1007/978-3-030-32618-0

(C) Springer Nature Switzerland AG 2020

This work is subject to copyright. All rights are reserved by the Publisher, whether the whole or part of the material is concerned, specifically the rights of translation, reprinting, reuse of illustrations, recitation, broadcasting, reproduction on microfilms or in any other physical way, and transmission or information storage and retrieval, electronic adaptation, computer software, or by similar or dissimilar methodology now known or hereafter developed.

The use of general descriptive names, registered names, trademarks, service marks, etc. in this publication does not imply, even in the absence of a specific statement, that such names are exempt from the relevant protective laws and regulations and therefore free for general use.

The publisher, the authors, and the editors are safe to assume that the advice and information in this book are believed to be true and accurate at the date of publication. Neither the publisher nor the authors or the editors give a warranty, expressed or implied, with respect to the material contained herein or for any errors or omissions that may have been made. The publisher remains neutral with regard to jurisdictional claims in published maps and institutional affiliations.

This Springer imprint is published by the registered company Springer Nature Switzerland AG. The registered company address is: Gewerbestrasse 11, 6330 Cham, Switzerland 


\section{The Importance of Institutions in Social Reality}

We often consider language as a significant indicator of what is happening in the world - and rightly so. Indeed, language generally reveals the degree of respect that people have for institutions. And when this degree is low - that is, when someone does not grant the right respect to a given institution - we say that this lack of institutional respect must be underlined or even punished.

In fact, institutions are considered - sometimes with a hint of rhetoric - something that must be protected, defended, and removed from the sphere of power and conflict, not because they are extraneous to conflict but because they are interpreted as arbitrators that have the task, essential to any democracy, to represent the third party between the ones involved. To be or to represent an institution means precisely to be at a higher level, taking a neutral stance with regard to the parties involved, in order to formulate a judgment that is a guarantee of impartiality. In this sense, because it is impartial, an institution should also have the power and moral authority to represent all those who belong to it.

Therefore, one of the main characteristics of institutions, as well as of their representatives, consists in acting from a place that is neutral, not because it does not belong to anyone but because it belongs to all those who are represented by that institution. In this sense, we must also consider the institution as a common good. Institutions (entities such as states and governments but also universities, courts of justice, or parliaments) are therefore common goods - universals, in a way - that belong to all citizens of a State, to all the members of a community. Therefore, they must be treated with the same care and attention that we have, or should have, for the natural resources of the Earth, the common lands that belong to a nation, the seas or anything else does not belong to anyone, since, ultimately, it belongs to the sum of generations that have lived or will live on Earth.

That said, it is evident that the ontological question about the identity of an institution is crucial from a philosophical perspective. In order to answer the question of the nature of the power managed by institutions, one has to answer another question concerning the nature and identity of the things we call institutions. In other words, what are institutions? How can we define them, provided that it is possible to agree on a definition? 
Can they be considered as collective subjects, as claimed by some theorists, or do we have to understand them differently, as a class of specific objects with particular properties? And if we choose this second option, what kind of entity would they be, and what properties would define them? What kind of relationship is there between the institutions and the singular subjects? What and how many types of relationships can there be between institutions? The ontological inquiry therefore takes precedence to that of other areas of philosophy, especially political and moral philosophy, which deal with or refer to institutions. Many institutions are in fact political subjects - think of the States - and, at the same time, they are also the political instruments needed for the implementation of justice. In other words, institutions, whatever they may be, are inspired by justice and have the task of promoting it.

Whatever the metaphysical option we decide to adopt to describe the nature of institutions, another decisive question is that of their relationship with individuals. This is true whether we decide to interpret institutions as subjects that are other than individuals, that is, not coinciding with the sum of the individuals that compose them, or whether we decide to interpret them as collective subjects. Since existence over a considerable time span seems to be one of the properties that define the essence of what we call an institution, it is evident that, above all in the political and ethical debate, the question of trust between institutions and citizens is crucial. A relationship of trust seems to be a necessary condition for the institutions to be able to last over time and to carry out their task: namely, the protection of individuals also through the application of justice.

Finally, a last aspect to consider concerns the question of the relationship between institutions and those elements - such as norms, laws, and contracts - that have a normative basis. Can we reasonably understand normativity as the foundation of institutions? If so, should we think of normativity as external to the institutions or internal to them?

This volume collects contributions from various theoretical and methodological orientations, aimed at investigating the theoretical cores related to the nature of institutions, their identity, and the normativity which inspires and grounds them, with the goal of bringing the debate on institutions back to the center of social ontology.

Torino, Italy

Belgrade, Serbia

Tiziana Andina

Petar Bojanic 


\section{Contents}

1 Social Corporations as Social Institutions $\ldots \ldots \ldots \ldots \ldots \ldots \ldots$. 1 Raimo Tuomela

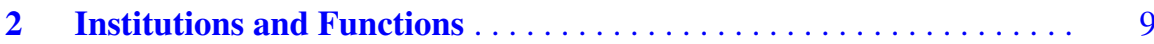
Francesco Guala and Frank Hindriks

$3 \quad$ Epistemic Virtues of Institutions . . . . . . . . . . . . . . . . . 21 Snježana Prijić Samaržija

4 What Is an Act of Engagement? Between the Social, Collegial and Institutional Protocols. Petar Bojanić

$5 \quad$ Play It by Trust: Social Trust, Political Institutions and Leisure ... . 51 Nebojša Zelič

6 Individual Morality and the Morality of Institutions ............ 73 Thomas M. Scanlon

$7 \quad$ States and Transgenerational Actions....................... 89 Tiziana Andina

8 From Capital to Documediality . . . . . . . . . . . . . . . . . 107 Maurizio Ferraris

9 The Basis of European Cooperation . . . . . . . . . . . . . . . . 123 Jonathan Wolff

10 Ways of Compromise-Building in a World of Institutions . . . . . . . 135 Emmanuel Picavet

Index........................................ 147 